\title{
RASCH, Manfred, PIERENKEMPER, Toni, REIMANN, Norbert, Adel als Unternehmer im bürgerlichen Zeitalter
}

\section{Thierry Jacob}

\section{(2) OpenEdition \\ Journals}

Édition électronique

URL : http://journals.openedition.org/ifha/1780

DOI : 10.4000/ifha. 1780

ISSN : 2198-8943

Éditeur

IFRA - Institut franco-allemand (sciences historiques et sociales)

Référence électronique

Thierry Jacob, «RASCH, Manfred, PIERENKEMPER, Toni, REIMANN, Norbert, Adel als Unternehmer im bürgerlichen Zeitalter », Revue de l'IFHA [En ligne], Date de recension, mis en ligne le 01 janvier 2009, consulté le 22 septembre 2020. URL : http://journals.openedition.org/ifha/1780 ; DOI : https://doi.org/ 10.4000/ifha. 1780

Ce document a été généré automatiquement le 22 septembre 2020.

(CIFHA 


\title{
RASCH, Manfred, PIERENKEMPER, Toni, REIMANN, Norbert, Adel als Unternehmer im bürgerlichen Zeitalter
}

\author{
Thierry Jacob
}

1 Issu d'un colloque organisé par les Vereinigte Westfälische Adelsarchive e.V., le Westfälisches Archivamt de Münster, M.R. et T.P. en 2004, cet ouvrage aborde une thématique plutôt inédite : la question des activités entrepreneuriales de la noblesse et la définition des rôles économiques qu'elle joue dans la sphère du capitalisme industriel. En effet, malgré le récent renouveau de l'histoire de la noblesse allemande, la question de ses activités économiques et de son implication dans la nouvelle donne économique engendrée par l'industrialisation est demeurée très en retrait.

2 L'objectif de l'ouvrage est non seulement de présenter des exemples précis et concrets d'implication entrepreneuriale nobiliaire, mais aussi de s'interroger sur les (éventuelles) spécificités des activités économiques de la noblesse, leurs tenants et aboutissants. Pour ce faire, l'ouvrage ne retient que les engagements opérés en dehors de la sphère agricole/sylvicole, ce qui constitue tout à la fois son originalité, mais aussi sa faiblesse car il laisse ainsi de côté l'une des dimensions les plus importantes de l'engagement entrepreneurial nobiliaire, celui qui se fonde sur l'exploitation de la partie agricole des domaines. De même, l'ouvrage ne se fixe pas de cadre géographique, mais balaie l'ensemble du territoire allemand, même si la noblesse westphalienne se trouve privilégiée. Enfin, les contributions se posent constamment la question des continuités/discontinuités dans le rapport de la noblesse à l'économie industrielle ; elles englobent aussi bien la période moderne que l'époque industrielle et s'attachent notamment à restituer le changement fondamental qu'a représenté le passage de la Frühindustrialiserung à la Hochindustrialiserung dans l'intensité et la nature des activités entrepreneuriales nobiliaires.

3 À l'article " programmatique ", posant les pistes de recherche, de M. RASCH et à celui de E. CONZE qui retrace les perspectives actuelles de l'histoire de la noblesse allemande des XIXe et XXe s., succèdent 14 monographies essentiellement familiales. Si les articles 
sur les magnats silésiens (T. PIERENKEMPER), singulièrement réhabilités ici dans leur rôle entrepreneurial, et sur la famille princière Thurn und Taxis (M. DALLMEIER) appréhendent des exemples déjà bien connus, quatre articles sur l'implication minière, papetière et chimique de familles de la noblesse westphalienne, abordent la question de l'engagement industriel sur la base des ressources du domaine (contributions de W. REININGHAUS, H. CONRAD, A. KUHN et H. BUDDE) tandis que celui de M. DIEFENBACHER étudie une famille du patriciat de Nuremberg impliquée dans l'industrie de la bière. Ces cinq articles se singularisent par la prise en compte d'un temps long d'analyse ainsi que par une réflexion sur la caractérisation qu'il convient d'appliquer aux rôles des nobles engagés dans les affaires. Si la noblesse du Mecklembourg (B. KASTEN) semble ne pas s'être impliquée outre mesure dans l'industrie sucrière régionale, ce qui resterait néanmoins à mieux démontrer, et si la famille royale du Wurtemberg (E. FRITZ) a longtemps privilégié les seuls investissements agricoles avant de s'intéresser avec prudence aux placements boursiers, E. KELL montre au contraire tout le dynamisme industriel de familles régnantes à l'exemple de deux familles princières du Palatinat à la fin de l'Ancien Régime. À l'exemple de Franz von Papen, futur chancelier de la fin de la République de Weimar, W. PYTA dépeint une forme fondamentale d'intervention de la noblesse dans la sphère économique, celle de l'utilisation des réseaux et de la position d'interface entre les élites. L'ouvrage s'intéresse également à la comparaison avec la bourgeoisie avec deux articles sur les modes de vie et les demeures de la noblesse et de la bourgeoisie des affaires (R. HILSENBECK sur les comtes Faber-Castell et S. STRAUSS sur les styles architecturaux vers 1900), tandis que M. REITMAYER rouvre le débat sur la " féodalisation des entrepreneurs » en montrant que les anoblissements n'assimilaient en rien la bourgeoisie des affaires à la noblesse.

Thierry JACOB (Université Lumière-Lyon II) 